\title{
A COMPARISON OF BRIBERY AND BIDDING IN THIN MARKETS
}

\author{
Paul J. BECK * \\ University of Illinois, Champaign, IL 61820. USA \\ Michael W. MAHER * \\ University of Michigan. Ann Arbor, MI 48109. USA
}

Received 10 June 1985

This paper compares bribery to competitive bidding in a government purchasing context. While competitive bidding is one method of procurement, bribery is a common alternative in many Third World countries. Although bribery is often considered to be the ethical antithesis of competitive bidding. the analysis shows there is a fundamental isomorphism between bribery and competitive bidding on the supply side of the transaction.

\section{Introduction}

Government contracts for goods and services are often awarded on the basis of competitive bidding, partly to reduce opportunities for bribe-taking. ${ }^{1}$ Various Third World countries, however. award such contracts administratively under the influence of bribery. In 1977, the Carter Administration sponsored Congressional legislation which now prohibits U.S. firms and individuals from paying bribes to foreign goverment officials. The purpose of this note is to model bribery as an arrangement for procurement in thin markets, and to compare bribery to the alternative of competitive bidding. Although bribery and bidding are considered to be ethical antitheses, we identify conditions under which these two exchange mechanisms exhibit a fundamental isomorphism. Specifically, we show that the same supplier will win the contract under both exchange mechanisms and that the expected net-of-bribes price paid by the purchasing country will be equal to the expected value of the winning bid. Under these conditions, controversies about the relative efficiency of bribery versus bidding may be moot. ${ }^{2}$

* We are grateful for comments from Vic Bernard, Gary Biddle. Michael Bradley, Joel Demski, Ronald Dye. John Eichenseher, Aneel Karnani, William Kinney, Glenn Loury, Sam Peltzman, David Sappington, Thomas Stober, Martin Zimmerman and participants in workshops at the Universities of Illinois and Michigan. This research was supported in part by the University of Illinois College of Commerce and The University of Michigan Business School.

1 See Alchian (1977), Rose-Ackerman (1978) and Holt (1980).

2 See Rose-Ackerman (1978) for a discussion of the comparative efficiencies of market and "corrupt" methods of dealing with government officials. Also see, for example, U.S. House of Representatives (1977) for political debate about the inefficiency of bribes to foreign government officials. 


\section{The bribery model}

Corporate filings with the Securities and Exchange Commission indicate that bribes to foreign government officials usually take the form of a commission. ${ }^{3}$ Typically, the government pays an inflated invoice price. and the supplier kicks back a portion of the invoice price to the official, a third party intermediary, or a designated bank account after the contract is awarded. ${ }^{4}$

We model the commission bribery transaction in a governmental procurement context in which the contract could he awarded competitively to the supplier submitting the lowest bid price or awarded at a predetermined price to the firm paying the largest bribe. In the bribery model, each potential supplier is assumed to negotiate privately with a governmental official. Hence, the information available to bribery participants is similar to the information available to bidders in that firms do not know the bribe offers of other firms. Suppliers are assumed to know the government's policy of awarding the contract to the firm offering to pay the largest commission bribe. Suppliers are assumed to know their own costs, but have incomplete information about competitors' costs and profits. Our analysis is restricted to symmetric games in which firms' information is modelled by the distribution $F(z)$, which is twice differentiable and an increasing function of $z$. Given these assumptions, $B(z)$ has an inverse which is denoted by $\pi(\cdot)$ and, by definition, $\pi(B(z))=z$.

We use the following notation in the models:

$P: \quad$ the contract invoice price.

c: $\quad$ the cost of supplying the product (excluding bribes).

$z=P-c:$ the gross profit from the contract.

$B: \quad$ the bribe to be paid to the government official,

$F(z)$ : the cumulative probability distribution for $z$, defined over the interval $[\underline{z}, \bar{z}]$, where $z \geq 0$, and

$n$ : the number of firms competing for the contract.

\section{Suppliers' response function}

Assuming that all firms employ a common strategy, $B(z)$, and behave independently, the largest bribe will be paid by the firm having the largest profit, and the associated probability is $F\left(z_{i}\right)^{n-1}$. Since $F\left(z_{i}\right)^{n-1}=F(\pi(B))^{n-1}$, the $i$ th firm's expected payoff is

$\mathrm{E}[\phi(B)]=\left[z_{i}-B\right] F(\pi(B))^{n-1}$,

where $E$ denotes the expectation operator and $\phi(B)$ is the payoff from bribe $B$.

Proposition 1. Given the above assumptions, the (symmetric) equilibrium bribery strategy for the ith firm is

$B\left(z_{i}\right)=z_{i}-\int_{z}^{z_{i}} F(t)^{n-1} \mathrm{~d} t / F\left(z_{i}\right)^{n-1}, \quad i=1, n$.

where $t$ is a dummy variable of integration.

\footnotetext{
"Detailed descriptions of these brihery activities can be found in U.S. Securities and Exchange Commission (1976), filings on 8-K and 10-K forms with the Securities and Exchange Commission. and in Greanas and Windsor (1982).

4 See descriptions of bribery transactions in Lockheed Corporation [U.S. Securities and Exchange Commission (1979)], In re sealed case [U.S. Court of Appeals (1982)], and Greanias and Windsor (1982).
} 
Proof. The equilibrium bribery strategy is determined by differentiating eq. (1) with respect to $B$,

$(\mathrm{d} / \mathrm{d} B) \mathrm{E}[\phi(B)]=-F(\pi(B))^{n-1}+\left[z_{i}-B\right](n-1) F(\pi(B))^{n-2} f(\pi(B)) \pi^{\prime}(B)$.

Since $B=B(z)$ and $\pi(B(z))=z$, it follows that $\pi^{\prime}(B(z))=1 / B^{\prime}(z)$. After making the appropriate substitutions, one can verify that the necessary condition for an interior optimum is that

$-B^{\prime}\left(z_{i}\right) F\left(z_{i}\right)^{n-1}+\left[z_{i}-B\left(z_{i}\right)\right] F\left(z_{i}\right)^{n-2} f\left(z_{i}\right)=0$.

Note that (4) is a linear differential equation whose solution is

$F\left(z_{i}\right)^{n-1} B\left(z_{i}\right)=\int_{z}^{z_{i}}(n-1) F(t)^{n-2} f(t) t \mathrm{~d} t+k$,

where $k$ is a constant of integration. Integrating the right-hand side of (5) by parts, one can verify that

$\int_{\underline{z}}^{z_{i}}(n-1) F(t)^{n-2} f(t) t \mathrm{~d} t=z_{i} F\left(z_{i}\right)-\int_{z}^{z_{i}} F(t)^{n-1} \mathrm{~d} t$

Substituting the right-hand side of (6) into (5) and dividing by $F\left(z_{i}\right)^{n-1}$,

$B\left(z_{i}\right)=z_{i}-\int_{z}^{z_{i}} F(t)^{n-1} \mathrm{~d} t / F\left(z_{i}\right)^{n-1}+k / F\left(z_{i}\right)^{n-1}$.

One can verify that, as $z_{i} \rightarrow \underline{z}$, the first term on the right-hand side has a limit of $\underline{z}$ and the second term has a finite limit using L'Hospital's rule. Therefore, $k$ must be identically zero because otherwise the bribe would be infinitely negative for $k<0$ or else violate the monotonicity property for $k>0$. The resulting bribery strategy can be shown to be consistent with a Nash equilibrium by verifying that $B\left(z_{i}\right)$ is a best-response when other competitors also employ $B(\cdot)$. Q.E.D.

Proposition 1 indicates that, in equilibrium, each firm submits a bribe offer which represents a markdown from its potential gross profit. The markdown term can be analyzed further by manipulating eq. (2) algebraically to obtain the following equivalent expression:

$B\left(z_{i}\right) F\left(z_{i}\right)^{n-1}=(n-1) \int_{z}^{z_{t}} t \cdot F(t)^{n-2} f(t) \mathrm{d} t$.

The left-hand side of (8) is the expected value of the bribe paid by the $i$ th firm, while the right-hand side is the expected gross profit of the firm submitting the second largest bribe (given that the $i$ th firm submits the largest bribe). Thus, (8) indicates that the $i$ th firm's expected bribe is effectively bounded by the expected gross profit of the second lowest cost firm. A further property of the bribery model in (2) is that the expected bribe paid to the governmental official is a non-decreasing function of $n$. Increased competition among firms affects the equilibrium bribe by increasing the probability of including the most profitable (lowest cost) producer and by inducing firms to become more aggressive. A statistical explanation is that, as the number of firms increases, the largest bribe ( $n$th order statistic) converges in mean square to the (finite) upper support of the industry gross profit distribution. Furthermore, the difference between the expected values of the $n$th and $n-1$ order statistics also can be shown to be a decreasing function of $n$. Hence, the governmental official is able to exploit the thinness of the market by extracting producers' surplus in the form of a bribe. 


\section{Bribery and bidding institutions}

The isomorphism between the bribery and bidding institutions is now established in two propositions. Proposition 2 presents the equilibrium bidding strategy for a game in which competitors have the same amount of information and costs as in the bribery model presented above. Proposition 3 then shows that, for a given contract price, the expected return to each firm from the equilibrium bribery strategy is the same as the expected return from the equilibrium bidding strategy derived ahove.

Proposition 2. Assuming that each firm knows its own cost and assesses a common distribution of costs for competitors $G(c)$, the equilibrium bidding strutegy is

$\hat{B}(c)=c+\int_{c^{c}}^{\bar{c}}[1-G(s)]^{n-1} \mathrm{~d} s /[1-G(c)]^{n-1}$.

where $\bar{c}$ is the upper support of $G(\cdot)$ and $s$ is a dummy variable of integration.

Proof. The equilibrium strategy can be derived using an approach similar to that in Proposition 1. Interested readers can obtain the details of the derivations from the authors.

We now compare the expected payoffs from the equilibrium bidding strategy in (9) with those from the equilibrium bribery strategy in (2).

Proposition 3. For a given contract price, $P$, firms' expected payoffs from the equilibrium bribery strategy are equal to the payoffs from the equilibrium bidding strategy.

Proof. The expected net payoff to a firm employing the equilibrium bribery strategy is obtained by substituting (2) into (1),

$$
\begin{aligned}
\mathrm{E}\left[\phi\left(B\left(z_{i}\right)\right)\right] & =\left[z_{i}-\left(z_{i}-\int_{\underline{z}}^{z_{i}} F(t)^{n-1} \mathrm{~d} t / F\left(z_{i}\right)^{n-1}\right)\right] F\left(\pi\left(B\left(z_{i}\right)\right)\right)^{n-1} . \\
& =\int_{\underline{z}}^{z_{i}} F(t)^{n-1} \mathrm{~d} t .
\end{aligned}
$$

The expected net payoff from the equilibrium bidding strategy is

$$
\mathrm{E}\left[\phi\left(\hat{B}\left(c_{i}\right)\right)\right]=\int_{c_{i}}^{\bar{c}}(1-G(s))^{n-1} \mathrm{~d} s .
$$

By definition of the cumulative distribution function,

$$
F\left(z_{i}\right)=\operatorname{Pr}\left(z<z_{i}\right)
$$

Recalling that $z=P-c$ and $z_{i}=P-c_{i}$,

$$
\begin{aligned}
\operatorname{Pr}\left(z<z_{i}\right) & =\operatorname{Pr}\left[(P-c)<\left(P-c_{i}\right)\right], \\
& =\operatorname{Pr}\left(c_{i}>c\right), \\
& =1-G\left(c_{i}\right) .
\end{aligned}
$$


Thus, $F(z)=1-G(c)$ point-wise. Since $\underline{z}=P \quad \bar{c}$ and $\bar{z}=P-\underline{c}$, the range of integration in (11) is also consistent with (12). This can be verified by recognizing that firm $i$ will win the symmetric bidding game when $c_{j}>c_{i}$ for $i \neq j, j=1, n$. But $c_{j}>c_{i}$ implies that $P-c_{1}<P-c_{i}$, so $z_{1}<z_{i}$, for $i \neq j, j=1, n$. Finally, the reversal in the direction of integration in (12) relative to (11) takes into account that $F\left(z_{i}\right)^{n-1}$ is an increasing function of $z_{i}$ over $[\underline{z}, \bar{z}]$ while $\left[1-G\left(c_{i}\right)\right]^{n-1}$ is a decreasing function of $c_{i}$ over $[\underline{c}, \bar{c}]$. Hence, the expected net payoffs in (11) and (12) are equal. Q.E.D.

The isomorphism between the equilibrium outcomes of the bidding and bribery games can be explained by the fact that the bribe actually is a covert discount paid by the supplier to the government official, rather than to the state. In effect, the government official implicitly conducts a covert bidding game in which the purchase is made at the lowest bid price and then resold at the invoice price, $P$. Since the contract is awarded to the same supplier and the same net-of-bribes price is paid by the government, both institutions are equally effective in extracting suppliers' surplus. Hence, in the absence of penalties for bribery. suppliers will be indifferent between paying bribes or discounting the selling price to the purchasing country.

\section{Conclusions and implications}

This paper has presented and compared an equilibrium model of bribery to a competitive bidding model. For a predetermined contract price, the bribery model was shown to be isomorphic to the bidding model in that the same firm won the contract and the government paid the same net-of-bribes purchase price. These results imply that, in the absence of penalties for bribery, supplier firms would be indifferent between bribery and bidding institutions. It all suppliers face the same penalty, then the equilibrium bribe would be reduced by the amount of the penalty, and the isomorphism between bribery and bidding would be retained. This isomorphism on the supply side may explain why exporting countries (except for the United States, after 1977) generally do not impose penalties for paying bribes to government officials in importing countries where bribery is legal.

\section{References}

Alchian. Armen A.. 1977. Electrical equipment collusion: Why and how. Economic forces at work (Liberty. Indianapolis. IN) 259-269.

Greanias, George C. and Duane Windsor, 1982, The foreign corrupt practices act (Heath. Lexington, MA).

Holt, Charles A., Jr., 1980, Competitive bidding for contracts under alternative auction procedures, Journal of Political Economy 88, 433-445.

Rose-Ackerman, Susan, 1978, Corruption: A study in political economy (Academic Press, New York).

U.S. Court of Appcals, District of Columbia Circuit, 1982, In re sealcd casc, no. 81-1717, April 23, 676 Federal Reporter. 2d Series, 793.

U.S. House of Representatives, 1977, Unlawful corporate payments act of 1977: Hearings on H.R. 3815, 95th congress, first session.

U.S. Securities and Exchange Commission, 1976, Report on questionable and illegal corporate payments and practices (Securities and Exchange Commission, Washington, DC).

U.S. Securities and Exchange Commission, 1979, Lockheed Corporation, Form 8-K, Feb. 